\title{
ULRIK SCHMIDT
}

Ph.d., videnskabelig assistent ved Institut for Engelsk,

Germansk og Romansk, Københavns Universitet.

\author{
MUSIK OG DESIGN \\ PHIL SPECTOR OG LYDFLADENS \\ MEDIALISERING \\ MUSIC AND DESIGN \\ PHIL SPECTOR AND SOUNDSCAPES \\ MEDIATIZATION
}

\begin{abstract}
Phil Spector is often referred to as one of history's first true music producers, and his famed 'Wall of Sound' has been the model for many future musical productions. However, Spector's productions can also be seen as an early manifestation, among others, of a much more general change in the auditory popular culture around 1960 away from the conventional approach to musical sound as something that depends primarily on a musical performance and secondarily its technical reproduction towards a conception of music as a form of design. Hence, Spector's productions make a favorable material for a more general investigation of the relationship between music and design. Despite the rather extensive literature on Spector and his music, and on sound recording and sound production in general, the different aspects of Spector's design have not yet been the subject of a broader phenomenological and aesthetic investigation. "Music and Design" explores the key elements in Spector's musical project through an analysis of his use of repetition, accumulation and synthetized sound in hit recordings such as He's a Rebel (1962) and Be My Baby (1963). It is argued that Spector's productions are basically characterized by a displacement of the auditory focus from external media conditions, to musical sound as simultaneously a more synthetic and mediatized as well as more massive and 'massified' soundscape. This mediatization of the soundscape would later constitute a predominant aesthetic model not only in current music production, but in modern sound design in general.
\end{abstract}

KEYWORDS I Sound design, music produktion, aesthetics, Phil Spector, Wall of Sound, sound density, mass culture, pop, 1960's.

Opfindelsen af lydoptagelsen i sidste del af det I9. århundrede og den senere kommercielle udbredelse af fonogrammet udvidede rammerne for den musikalske oplevelse radikalt. Ikke blot musikken, men hele forståelsen af, hvad lyd er, begyndte at ændre sig grundlæggende. Men den dybe kulturelle og æstetiske effekt af 
lydteknologien, som vi i dag, bevidst eller ej, er fuldt bekendt med, konstituerede sig dog historisk set først relativt sent i forhold til introduktionen af selve teknologien. Den teknologiske indsættelse af fonogrammet som et yderligere led i den musikalske tilblivelsesproces fra et eventuelt partitur over opforelse til lydoptagelse var længe ikke noget, der fundamentalt forskød musikbegivenhedens væsentlige tidsrum og indsatte et nyt telos for den musikalske tilblivelsesproces. Fonogrammet udvidede og mangfoldiggjorde måske vejene mod målet, men selve målet forblev længe det samme. Partituret var tidligere - på trods af dets enorme betydning for udviklingen af den vesterlandske musik - hovedsageligt blevet opfattet som et led i den musikalske tilblivelsesproces, der lå før den egentlige og primære, klingende musikalske begivenhed. På samme måde forblev lydoptagelsen i de første mange årtier af dens historie stadig $i$ al væsentlighed betragtet ikke blot som en materielt forvrænget lagring $i$ et nyt og fundamentalt anderledes medium end det oprindelige, men også som en tidsligt forskudt, forsinket, gengivelse af den musikalske begivenhed, en re-produktion. Det var stadig i den musikalske opforelse, at musikken realiserede sit fulde potentiale og materialiserede sig i hele sit væsen for lytteren. Æstetisk set forblev fonogrammet - fra den globale klangflade og ned i de lokale lydlige detaljer - længe et minde om en begivenhed, der allerede havde fundet sted.

I dag er oplevelsen og opfattelsen af fonogrammet som bekendt ændret. Fonogrammet lyder og opfattes i dag i altovervejende grad som produceret og producerende, snarere end reproduceret og reproducerende. Den afspillede musik er ikke længere et maskinelt registreret og forskudt vidnesbyrd om noget forhenværende, men noget der udgør sin egen oprindelse. ${ }^{89} \mathrm{Vi}$ har med andre ord været vidne til et historisk omslag - indtruffet i perioden mellem den tidlige reproduktionsteknologiske lydkultur og vor tids produktionskultur - der tendentielt har forskudt opfattelsen og iscenesættelsen af den konstituerende musikalske begivenhed væk fra den originale, førmediale opførelse til selve fonogrammet og dets tekniske afspilning.

I tæt forbindelse hermed forrykkedes perspektivet på musikkens klanglige væsen fra det før-reproducerede og reproducerede og hen mod fonogrammatisk produktion. Dette skift i opfattelsen af, hvad en produceret, fonogrammatisk lydbegivenhed er, kommer eksempelvis til udtryk hos produceren, lyddesigneren og ambient musik-komponisten Brian Eno, der i 1983 hævdede, at "plader [ ] ikke har noget at gøre med opførelser. [] Så jeg har længe tænkt, at hvis jeg laver plader, vil jeg ikke tænke $i$ at fremkalde en erindring om en opførelse [], men i at lave et lydstykke [a piece of sound] []" (Eno citeret fra Tamm 52) Man kan hævde, at fremvæksten af denne fornemmelse for produktion og for teknisk afspillet lyd i lige så høj grad kendetegner lydoptagelsens så ofte pointerede fundamentale indvirkning på musikkulturen i det 20. århundrede, som selve muligheden for at

89 Det er selvsagt ikke mit ønske, at tale for et absolut omslag fra reproduktion til produktion, men alene at påpege en markant tendentiel ændring i opfattelsen af afspillet lyd. Fonogrammet kan i dag naturligvis stadig iscenesættes ud fra reproduktions-æstetiske præferencer og virkemidler sådan som det for eksempel ofte er tilfældet i forbindelse med indspilninger af jazz og partiturmusik. 
reproducere den førmedierede verden, om end omslaget mod produktion umuligt kan tænkes løsrevet fra denne mulighed.

Dette omslag i den æstetiske kultur fra reproduktion til produktion kan mere præcist karakteriseres som en forskydning i opfattelsen af den paradigmatiske musikoplevelse væk fra lytterens perceptuelt uforhindrede, rumtidslige nærvær med opførende enkeltindivider, som i kraft af deres musikalitet og performative instrumentbeherskelse frembringer og iscenesætter en musikalsk begivenhed, og hen imod den medialt distancerende, teknologisk foranstaltede lydbegivenhed, som udfolder sig i det afspillede medie uden nogen essentiel fænomenal forbindelse til en førproduceret verden. Strukturen: [partitur] $\rightarrow$ OPFØRELSE $\rightarrow$ [fonogram], hvor live-opførelsen udgør det centrale og eneste essentielle moment, er den struktur som præger såvel den akustiske musikbegivenhed som den lydlige reproduktionsæstetik. Denne struktur bliver efterhånden overtaget af en ny generel struktur: [partitur] $\rightarrow$ FONOGRAM $\rightarrow$ [opforelse], hvor fonogrammet indsætter sig som processens helt centrale og eneste essentielle moment, og hvor en eventuel live-opførelse snarere udfolder sig som en rekonstruktion eller viderefortolkning af den oprindelige og originale studieindspilning, frem for at danne udgangspunktet herfor. (Auslander 73)

I tråd hermed ændredes musikproduktionens funktioner fra at have kredset om den musikalske opførelse til at sætte det tekniske indgreb $\mathrm{i}$ et foreliggende lydmateriale som omdrejningspunkt: fra den egenhændige håndtering, formning og produktion af en klang til det at virke ind på noget, som allerede er $i$ gang med klangligt at manifestere sig. Hvor opførelsen i en direkte og henvendende kommunikation stadfæster et rumtidsligt nærvær mellem musiker og publikum, evt. gennem repræsentation, udfolder indgrebet sig snarere som en gestus, der netop er karakteriseret ved manglen på direkte og umedieret henvendelse - og ofte endda manglen på mulighed for direkte og umedieret henvendelse - en mangel, der $\mathrm{i}$ stedet bidrager til at stadfæste og forstærke forbindelserne mellem lydmediet og dets forførte publikum. På den måde begynder musikken at udvikle sig til en form for design..$^{\circ}$

\section{Design og medialisering}

Den her skitserede udvikling må mere generelt forstås som manifestationen af en ny fornemmelse i kulturen, der har indsat designet af fænomenverdenen som

90 Jeg anser den her skitserede historiske ændring af fokus fra reproduktion til produktion for at være ganske ukontroversiel. I diskussionen af musikproduktion har faglitteraturen - når den direkte omhandler æstetiske spørgsmål og ikke begrænser sig til kultursociologiske problemstillinger - dog i væsentlig grad fokuseret på pladeindspilning som noget, der hovedsageligt udfolder sig i spændingsfeltet mellem opførelse og teknisk gengivelse. Det er for eksempel tilfældet hos såvel Michael Chanan, Albin Zak, Mark Katz og Greg Milner. En undtagelse er Virgil Moorefield, hvis fokus ligger på den historiske forskydning af pladeindspilningens hovedanliggende fra det, han kalder "virkelighedens illusion" til "illusionens virkelighed". (xiii) Det er de fænomenale og æstetiske implikationer af denne forskydning, som er genstanden for nærværende undersøgelse. 
det væsentligste udgangspunkt for æstetiske oplevelser. Naturligvis har en sådan design-sensibilitet aldrig helt afløst tidligere fornemmelser - heller ikke i nutidens musikkultur - men den har dog klart fortrængt dem til sekundære positioner. Den æstetiske omgang med musik er ikke længere så meget funderet i det unikke fælles møde mellem lytter og opført værk som i fornemmelsen for design. Det er en fornemmelse, der sværmer for det virtuose indgreb og det unikt medialiserede moment og som søger dem i de teknisk producerede produkter og deres implicitte møde med masserne.

Denne - om end relativt forsinkede - udvikling af en designfornemmelse i kølvandet på den tekniske lydfrembringelse har resulteret i en ændret æstetisk iscenesættelse af lydens formelle og materielle egenskaber, som adskiller sig væsentligt fra både en akustisk lydbegivenhed og fra den lydlige reproduktion, som den udviklede sig i første del af det 20. århundrede. En violin, for eksempel, kan spilles med eller uden vibrato, pizzicato eller med bue, kraftigt eller svagt, med hurtige eller langsomme strøg etc. Men efter håndteringen af lyden klinger den frembragte lyd under alle omstændigheder i konstant og uløselig idiomatisk forbindelse med selve violin-instrumentet som lydens konkrete akustiske kilde. Det er violinens egne, iboende klanglige potentialer, der er blevet udnyttet, og som tilfører lyden dens specifikke klangkvaliteter som netop klangen af en violin. Reproduktionen fastholder grundlæggende dette forhold. Den unikke violinlyd kan kopieres, opklippes, forskydes, men forbliver dog fundamentalt forbundet med sin oprindelige lydkilde. Med designet begynder dette bånd mellem lyden og dens kilde at brydes. En akustisk violin, spillet live og uden kabler, altså håndteret, umedieret og ikke-reproduceret, og den samme violin teknisk reproduceret, altså optaget og medieret, står $i$ produktionen ikke længere i noget direkte tidsligt eller rumligt forhold til hinanden i den forstand, at den ene må tænkes og forstås som et rumtidsligt forskudt produkt af den anden.

En reproduceret lyd og en designet lyd begynder på den måde at antyde to principielt helt uafhængige måder at fremtræde for sansningen på $\mathrm{i}$ tid og rum, to lydæstetiske grundudtryk, to fundamentale og fundamentalt forskellige former for lyd. ${ }^{91}$ Med produktionen påbegyndes en æstetiseret opløsning af reproduktionen, og dermed også en opløsning af spændingen mellem den reallydlige verden og dens repræsentation, i oplevelsen. Det er den astetiske effekt, det vil sige den sansemæssigt udfoldede virkning (enten subliminal eller mere bevidst), af denne opløsning, som er fokus for nærværende tekst. Formålet er at undersøge det musikalske design, og

9I Det var en central pointe hos Walter Benjamin (1980), at en af de grundlæggende forskelle mellem auratisk nærvær og distanceret reproduktion ligger i den måde, hvorpå de på forskellig vis gav fænomenet tidslig og rumlig forankring: fra det ikke-medieredes rumtidslige nærvær til reproduktionens spatio-temporalt ulokaliserbare gentagelighed. Det, jeg ønsker at understrege her, er, at reproduktionen, trods dens rumtidslige løsrivelse, æstetisk set alligevel funderer sig på den før-reproducerede verden, altså på det rumtidslige nærvær, som den løsriver og gentager i reproduktionen. Produktionen, derimod, adskiller sig æstetisk set grundlæggende fra såvel reproduktionen som den før-reproducerede akustiske verden ved i princippet ikke længere at koble an til denne realverden som dens grundlag og oprindelse. Produktionen bliver produktion i det øjeblik, den indsætter sig som sin egen oprindelse. 
mere generelt lyddesign, som en række specifikke formelle og materielle egenskaber ved det teknisk afspillede lydfanomen. Et design, hvis væsentligste kendetegn netop skal findes $i$ den perciperbare forskydning af reproduktionen hen imod en mere eller mindre fuldstændig mediemæssig lydudfoldelse.

Der må i denne forbindelse skelnes tydeligt mellem henholdsvis mediering og medialisering. Hvor mediering, i tråd med den almindelige brug af begrebet, forstås som den teknisk reproducerende formidling og udsendelse af et fænomen i mediet, foreslår jeg at anvende begrebet medialisering om den proces, hvor fænomener præges formelt og materielt af det medium, som de udfolder sig i. Medieringen fører fænomenet fra et sted til et andet og omformer det i en mimetisk proces; medialiseringen gør mediet til stedet for dets fremtrædelse. Mediering er teknisk reproduktion af en virkelighed, som ikke oprindeligt tilhører det medium, hvorigennem det udsendes; en medial gengivelse af en præmedialiseret verden eller en medial verden uden for det pågældende medium. Medialisering, derimod, opererer principielt ikke længere med en præmedialiseret verden eller med andre mediale verdener, men indsætter i stedet den mediale processering og produktion som sit eneste grundlag for udsendelsen. Medialisering bliver på den måde en æstetisk perciperbar formel og materiel egenskab ved lydfænomenet, der er mere eller mindre fuldt ud defineret ud fra de teknologiske, materielle og formelle egenskaber ved selve lydmediet og den mediemæssige tilblivelsesproces. En mediering har således altid et medialiseret aspekt, men ikke omvendt. Frem for at lægge sig efter reproduktionen sætter medialiseringen sig snarere igennem i oplevelsen som den første produktion, som et aspekt af den mediemæssige frembringelsesproces, der alene finder sted i og ud fra mediet, hvormed det indsætter sig som det medialiserede fænomens eneste oprindelse.

Det er i fornemmelsen af lydenes medialiserede løsrivelse fra deres kilder i den førmediale verden, at vi finder grundlaget for det gennemgribende musikalske design og den dannelse af virtuelle rum i musikken, som kendetegner vor tids musikproduktioner. Lyddesign er for så vidt mere end noget andet en lydmedialiserende proces, hvis primære formål netop er at bringe lydene i tættere materiel og formel forbindelse med det medium, hvori de udfolder sig. Fra et æstetisk perspektiv - det vil sige anskuet med henblik på dets betydning for den sansemæssige oplevelse af fænomenet - er design i den forstand ikke en efterfølgende overfladebehandling af reproducerede originallyde, men en effekt i oplevelsen, der angår lydenes udformning og produktive tilblivelse i mediet.

Den flerspors lydoptagelses- og redigeringsteknik, der blev muliggjort af magnetbåndets introduktion i den amerikanske pladeindustri i I950'erne, og som for alvor blev udbredt i lydstudier verden over efter 1965, havde ikke blot specifik betydning for den teknologiske udvikling af nye reproduktionsformer, men spillede også en stor rolle i den generelle kulturelle forankring af lyddesignet. Men fornemmelsen for musikalsk lyddesign går betydeligt dybere end forkærligheden for det velproducerede og afbalancerede lydbillede, i hvis teknologiske udviklingshistorie multitrack recording utvivlsomt udgør en milepæl. Det musikalske lyddesign kan 
naturligvis på ingen måde ses som noget brud med idealet om højest muligt $\mathrm{S} / \mathrm{N}$ (signal to noise ratio) i lydoptagelsen; endsige med hi-fi-industriens grundtanke om, at den ideelle mediering findes i den tekniske reproduktion, der besidder størst nøjagtighed og troskab (bigh fidelity) i forhold til den virkelighed, som den skal lagre og videreformidle..$^{2}$ Men sådanne ønsker om de mest uforstyrrede lydgengivelser udspringer ikke af fornemmelsen for design. Det tilhører en reproduktions-sensibilitet, hvis æstetiske fornemmelse er rettet tilbage mod karakteren af relationen mellem den førmedierede verden (den musikalske opførelse etc.) og dens tekniske lagring. Designet opløser ikke nødvendigvis fuldt ud denne relation mellem det opførte og dets tekniske lagring, mellem den objektive verden og dens reproduktion. Men dens kvalitet og karakter udgør ikke længere nogen væsentlig æstetisk parameter i opbygningen af det designede lydrum. Design-sensibiliteten fornemmer i musikæstetisk forstand ikke længere en musikalsk virkelighed før medialiseringen. Den indgribende gestus i et allerede medialiseret materiale er blevet momentet for den designede lyds egentlige tilblivelse.

\section{Phil Spector og girl group-ceraen}

Fornemmelsen for og iscenesættelsen af fonogrammet som en form for medialiseret lyddesign er naturligvis noget som har udviklet sig gradvist op gennem lydteknologiens historie. Det er ikke muligt at spore et brat historisk skift, hvor efter alt var anderledes. Men dog kan man udpege nogle historiske begivenheder, der i særlig grad viser tegn på et begyndende omslag i sensibilitet væk fra en reproduktionsæstetik og i retning af medialisering og fonogramdesign, og som derfor er af særlig kulturhistorisk og æstetisk interesse for en dybere forståelse af moderne lyddesigns udvikling og grundlæggende virkemidler. Et af de første, markante eksempler på en sådan begivenhed finder man i New York i begyndelsen af 1960 erne, nærmere bestemt med Phil Spectors innovative hit-produktioner fra årene 1962-63. Spector var en af de første producere, som blev anerkendt for at have sin egen lyd, en særlig Phil Spector Sound. (Jf. Thebérge I92; Zak 59f; Milner I52; Moorefield 9) Med Spector begynder man i musikken mere entydigt at kunne spore en klanglig formgivning, hvor designet ikke længere spiller en sekundær, ornamental rolle i lydproduktionen, men er blevet den medialiserende grund, hvor fra lydmaterialet udspringer som produceret. Med Spector finder det medialiserede og designede element af pladeindspilningen, hvis fravær i dag synes utænkeligt, med andre ord en af sine første udfoldelser som en gennemgribende æstetisk egenskab ved musikkens lydlige fremtrædelse. Sammenlignet med tidligere indspilninger lyder Spectors udgivelser kort og godt betydeligt mere designet. De lyder som om, at de stammer fra det medie, hvori de udfolder sig.

92 Begge dele var noget, der langsomt begyndte at aftegne sig som et ideal i midten af I920'erne (Jf. Thebérge 192). 
Spectors historiske betydning for udtoningen af reproduktionsæstetikken og hans kreative ophøjelse af den musikalske produktion til en væsentlig musikæstetisk parameter, angik ikke så meget en innovativ brug af nyopfundne produktions- og postproduktions-teknologier. Mange af de i denne sammenhæng vigtigste af sådanne teknologier blev forst introduceret i sidste del af ig6o erne, og da det skete udviste Spector ingen synderlig interesse i dem. Det var altså ikke - sådan som man ellers umiddelbart kunne foranlediges til at tro - ved at bryde med reproduktionsteknologien, at Spector udviklede sin sound. Spectors design ligger ikke efter reproduktionen. Det bliver til under indspilningen som en del af optagelsesakten. Den musikalske organisation i komposition og opførelse var stadig eneste middel og materiale for hans medialisering af lydfladen. Netop af denne grund er Spectors tidlige girl group-produktioner særligt frugtbare studieobjekter i en afsøgning af det musikalske lyddesigns fænomenale og æstetiske implikationer. Det er her designet så at sige optræder i sin rene form, før pladeindustrien udviklede nye teknologiske produktionsformer og standardiserede effektbearbejdninger i form af analoge og digitale effektmaskiner, waveform modifiers, sampling, sequencing, digital lydredigering, DAWs (digital audio workstations) osv. Spectors produktioner kan med andre ord vise os, hvad der er på færde, når designet ikke udspringer af effekter og teknologier alene, men - delvist uafhængigt af den teknologiske udvikling i øvrigt - opbygger en gråzone mellem reproduktion og produktion, mellem mediering og medialisering, hvori den medierede lyd kan begynde at træde frem som en form for design.

Den mere generelle sensibilitet, som Spector giver lyd, havde sit kulturelle udspring i den spirende amerikanske populærkultur i begyndelsen af ig6o erne. Denne periode omkring I960-63, som man ofte betegner girl group-craen, var en periode præget af rock n roll, farvestrålende modetøj, jukeboxes, stilfulde frisurer og teenagers. Det var tiden umiddelbart efter den unge Elvis popularitet havde nået sit højdepunkt, og umiddelbart før den britiske invasion af amerikansk musikkultur - med bands som The Beatles, The Rolling Stones, The Animals etc. - der på mange måder skulle præge den musikalske populærkultur i resten af 60 ere. En af de mest betydningsfulde institutioner for den lydlige iscenesættelse af girl group-æraens populærkultur var den berømte Brill Building i New York og de pladeselskaber, der var organiseret omkring den. Den omfangsrige produktion af rock n roll-hits, der fandt sted her, var omkring 1960 fastlagt i en særdeles standardiseret procedure fra komposition til distribution, som for musikdelens vedkommende kan opsummeres i følgende typiske forløb: I) sangskriverpar (tekstforfatter og komponist) skriver materiale; 2) publishers viser materialet til eller opfører det for A\&R-personalet; 3) solisterne ser det accepterede materiale og hyres; 4) man finder en arrangør, som udarbejder et detaljeret arrangement; 5) arrangøren hyrer en contractor, som igen hyrer studiemusikere; 6) solister og studiemusikerne kommer i studiet og lydindspilningen foretages under ledelse af arrangør, producer og teknikere. (Jf. Moorefield 6)

Efterhånden som bevidstheden om, at hit-produktion ikke alene angik kvaliteten af sang- og tekstkompositionen og dens mere eller mindre standardiserede 
opførelse, men også, og måske i lige så høj grad, den teknologiske indspilning og produktion af sangene på plade - en generel bevidsthed, der for alvor kom op til overfladen af musikbranchen netop i Brill Building-kulturen i sidste del af 5o'erne begyndte mange af de sangskriverpar, der var tilknyttet Brill Building at udvide deres virksomhed til også at omfatte arrangement, indspilning og produktion. Det berømte sangskriverpar Jerry Leiber og Mike Stoller var hovedfigurerne i denne begyndende opløsning af det standardiserede produktionsforløb. ${ }^{93}$ Fra alene at have stået for tekst- og melodi-siden og ellers overladt resten af forløbet til senere led $\mathrm{i}$ processen, overtog Leiber and Stoller i slutningen af 1950 erne helt producerrollen i studiet og begyndte at eksperimentere med virkningerne af forskellige spillemåder under indspilningsprocessen. Samtidig begyndte de at indoptage elementer fra andre musikgenrer så som latin-amerikansk musik og den klassiske orkestermusik $\mathrm{i}$ en på den tid efterhånden standardiseret rock $\mathrm{n}$ roll-instrumentation og dermed at udvide grænserne for, hvordan rock $\mathrm{n}$ roll kunne lyde. 94

Leibers og Stollers delvist frem-improviserede arrangementer og afsøgende indstudering $i$ studiet vidner om, at de var begyndt at bevæge sig hen imod en opfattelse af musikken som noget, der udfolder sig i en decideret optagelsesbegivenhed, i en act of recording. Men selvom Leiber og Stoller på den måde kan siges at udtrykke en begyndende fornemmelse for musikkens designede aspekt, kan lyddesignet dog endnu ikke siges at have sat noget entydigt og dybdeborende lydligt præg på deres produktioner. Man fornemmer på indspilningerne stadig tydeligt tilstedeværelsen af et orkester, der sammen med koret akkompagnerer forsangeren $i$ front i en reproduceret musikalsk begivenhed. Instrumentalisterne og vokalisterne musicerer stadig sammen. De er stadig recording artists, der opfører et stykke musik foran en mikrofon til lagring og senere distribution. De deler stadig det samme rum og den samme tid, som indspilningen reproducerer på fonogrammet. Af samme grund angår sangene og deres produktion i langt overvejende grad stadig den melodisk fængende kombination af toner og det veloplagte arrangement.95 Der er endnu ikke sat fokus på udformningen af en distinkt og dybtgående medialiseret lydflade, og dermed på skabelsen af et egentligt musikalsk lyddesign. Det er dette som ændrer sig med Phil Spectors produktioner årene efter.

Da Spector som 19-årig ankom fra Los Angeles til New York i 1960, fik han hurtigt en aftale om at fungere først som producerlærling og snart som ligestillet medproducer hos netop Leiber og Stoller. Året efter startede Spector sit eget pladeselskab, Philles Records, og blev eneproducer. Det var i den følgende, relativt

93 Leiber og Stoller havde årene før skrevet flere af Elvis Presleys største hits (f.eks. Jailhouse Rock (1956) og Hound Dog (1957)), og de var omkring I960 et af de mest succesfulde sangskriverpar tilknyttet Brill Building.

94 Et af de mest markante eksempler herpå er deres produktion af The Drifters There Goes My Baby (I959). Udover at have skrevet sangen, denne gang sammen med The Drifters forsanger Ben E. King, tilfører Leiber og Stoller for første gang i rock n roll strygere til lydbilledet og de giver, ligeledes for første gang, nummeret en karakteristisk latin-feeling.

95 "The genius of Leiber and Stoller s production of the Coasters" i slutningen af I950 erne, påpeger Ken Emerson for eksempel, "was their ability to create and choreograph painstakingly the illusion of high-spirit spontaneity." (56). 
korte, periode fra sommeren 1962 til efteråret 1963, at Spector fra pladeudgivelse til pladeudgivelse udviklede og nuancerede designet af sin berømte wall of sound. Det musiksyn og den produktionsform, som Spector konfektionerede i denne periode, bevarede han stort set uændret gennem resten af sin karriere. Til trods for at antallet af nye og banebrydende teknologiske foranstaltninger steg med stor hast i de efterfølgende år og begyndte at tage mere og mere plads i pladestudierne omkring ham, holdt Spector sig til grundtanken og grundteknikken bag de succesfulde girl group-produktioner fra karrierens allerførste år.

\section{Massifisering}

Den overordnede effekt af Spectors design kan samles i et enkelt begreb: massifisering. Massifisering forstår jeg som en immanent fortætning af lydmaterialet gennem ophobning og mangfoldiggørelse af dets dele. Som jeg skal demonstrere og diskutere i det følgende, præger massifisering Spectors produktion i så godt som alle aspekter af den lydlige tilblivelsesproces og må ses som hans uden sammenligning væsentligste designprincip. Samtidig er det i særdeleshed Spectors massifisering af lydfladen, der peger frem mod vor tids mere standardiserede, analoge og digitale design- og produktionsprincipper. Massifiseringseffekten udfolder sig hos Spector på to niveauer. For det første som en global udplanering og dehierarkisering af den overordnede lydflade gennem ophobning af lydobjekter. For det andet lokalt som en designet fortætning af det enkelte lydobjekt $\mathrm{i}$ kraft af en indre mangfoldiggørelse.

Første gang at de kvaliteter, der skulle udgøre kernen i Spectors massifiserede lyd, begyndte at vise sine konturer, var på hans produktion af The Crystals He's a Rebel (indspillet juli 1962). Spector videreførte og radikaliserede her Leibers og Stollers inddragelse af nye og mere perifere instrumenttyper i rock n roll-orkestrets klangflade. Sammenlignet med Spectors efterfølgende produktioner stod He's a Rebel rent klangligt stadig i tydeligt forlængelse af 50 ernes rock n roll-produktioner. Men en væsentlig forskel begynder dog diskret at træde frem i lydbilledet. Sammenlignet med rock $\mathrm{n}$ roll-indspilningernes karakteristiske klangrum med relativt klart adskilte instrumentgrupper og en relativt stor grad af klanglig nuanceforskel mellem nummerets forskellige passager, synes de klanglige forskelle på He's a Rebel $i$ højere grad at være udlignet $i$ en mere plan struktur. De enkelte elementer synes at miste deres individuelle nuancer og begynder at føje sig ind $i$ hinanden, at samle sig og danne en enhed.

Denne effekt skyldes Spectors introduktion af en ny indspilningsmetode. Det var under indspilningen af He's a Rebel, at Spector påbegyndte sin procedure med at lade de forskellige instrumentalister gentage små figurer og kadencer, ofte i flere timer i træk, indtil de besad den for ham helt rigtige klanglige fornemmelse. Denne indspilningsteknik, der var med til at gøre Spector berygtet blandt tidens studiemusikere, må ikke blot ses som et udtryk for professionel grundighed eller excentrisk stædighed. Teknikken havde tydeligvis i sig selv en æstetisk begrundelse. Den indeholdt potentialet for en særlig effekt, som netop består i tilføjelsen af en større 
grad af klanglig enhedskarakter. Dette skyldes flere forhold: Med reduktionen af instrumentalisternes musikalske råderum til den konstante repetition af et løsrevet udsnit, reducerer Spector den enkelte musikers mulighed for på konventionel vis at indgå $i$ et nuanceret og varieret sammenspilsmoment med de andre musikere $i$ opførelsen og eventuelt blive tilskyndet til at foretage individuelle, lokale prægninger af klangfeltet gennem diverse betoninger og variationer. Derudover eliminerer Spector med reduktionen til gentagelse enhver mulighed for både global og lokal musikalsk opbygning og kontinuert sammenkædning mellem nummerets forskellige elementer. Repetitionen af de løsrevne forløb var ikke et led i en optimering af den orkestrale indstuderingsproces. Den satte et gennemgribende præg på de isolerede lydlige forløb og klargjorde dem til optagelse. ${ }^{9}$

Med denne simple teknik indskrænker Spector studieinstrumentalistens råderum som musikalsk subjekt. Samtidig trodser han subtilt idéen om den musikalske komposition som et organisk udviklende dynamisk spændingsfelt. Resultatet af denne form for menneskelig sampler er en betydeligt mere standardiseret og maskinelt præcis menneskelig serieproduktion af ensrettende lydenheder. Spændingen mellem forskelle og nuancer erstattes af det sammes fortsættelse. Spector overtager måske brugen af det gennemgående riff eller hook fra I950 ernes rock n roll. Men det er samplingen - forstået som den afgrænsende fragmentering af kontinuiteter til gentagelige moduler - og de desubjektiverede musikeres maskinelt repetitive drift mod ensartethed, der begynder at give He's A Rebel træk af den wall of sound, som Spector skulle realisere i sin helt udfoldede form i månederne efter.

Med He's a Rebel havde Spector introduceret gentagelsen som indspilningsprocessens udgangspunkt. Under de efterfølgende indspilninger tager han en række yderligere designteknikker $i$ anvendelse, der alle ligesom sampling-metoden bygger på gentagelsesprincippet. Under indspilningen af Zip-A-Dee-Doo-Dab (indspillet august 1962) - Spectors næste udgivelse efter He's a Rebel - påbegynder han sin procedure med at ophobe musikere i studiet; en procedure, der skulle udgøre en af de helt centrale teknikker bag designet af hans wall of sound. Ligesom samplingen bidrog til en betydelig planering af det lydlige forløb gennem maskinel repetition af diskontinuerte fragmenter, bevirker denne ophobning af lydkilder en objektiviserende udjævning af lydenes immanente forskelligheder i klangrummet. Men hvor samplingen i højere grad angik en desubjektivering af musikernes spillemåde og planering af det overordnede musikalske forløb, bidrager mangedoblingen af lydkilderne nu direkte til lydfladen med en decideret klanglig effekt, der fortætter klangrummet og begynder at samle det til en egentlig lyd-flade. Effekten kommer allerede tydeligt til udfoldelse på Zip-A-Dee-Doo-Dah. Med undtagelse af en relativt

96 Når Albin Zak taler om, hvordan Spector med denne gentagelsesteknik "wanted to capture the feel and energi of live playing” (58) tager han i mine øjne alvorligt fejl. Det, som giver teknikken sin særlige æstetiske effekt - en effekt, der ikke blot angår Spectors særlige wall of sound, men peger direkte frem mod vor tids designæstetik centreret omkring sampling, looping og sequencing - er, at Spector reducerer energien i musikernes live-performance og derigennem frembringer en betydeligt mere standardiseret, anonym, desubjektiveret og materialiseret lyd, der bringer den tættere på det medie, hvori den skal udfolde sig som afspilning. 
distinkt perkussiv guitarfigur og kastagnetter i forgrunden, skiller nummerets enkelte instrumenter sig - i kraft af deres immanente mangfoldiggørelse - ud fra de andre i lydfladen $i$ et så begrænset omfang, at enhver klanglig rest af singularitet og individualitet $\mathrm{i}$ det musikalske sammenspilsrum synes opløst i en fortættet, objektiv og enhedslig masse af lyd.

Spector intensiverer sin mangfoldiggørelse af lydkilderne på de efterfølgende indspilninger, og effekten når sit klareste udtryk i sommeren 1963 på to af Spectors største hits, The Crystals' Da Doo Ron Ron (indspillet april 1963) og The Ronettes' Be My Baby (indspillet august 1963). Til indspilningen af Be My Baby havde Spector udvidet besætningen til at bestå af hele tre trommeslagere, tre bassister, mere end tre guitarister, mere end tre klaverer og cembaloer, tre eller flere blæsere på hver stemme i blæsersektionen, talrige percussionister etc. ${ }^{97}$ Men Spectors mangfoldiggørelse består vel at mærke ikke i tilføjelsen af flere stemmer, flere forskellige guitarfigurer for eksempel, i orkestret. Der er i stedet tale om en så vidt muligt præcis kopiering af et bestemt isoleret fragment, et bestemt sample, oven på sig selv i hele sin rytmiske og melodiske udformning. Mangfoldiggørelsen som effekt er hos Spector effekten af det samme gentaget, ikke horisontalt og serielt som en rækkefølge i tid og rum ligesom i sampling-teknikken - eller for så vidt som man så det i den samtidige amerikanske minimalisme hos komponister som Terry Riley, Steve Reich og Philip Glass - men derimod vertikalt gentaget. Masseeffekten i Spectors wall of sound bunder med andre ord ikke i introduktionen af et mere komplekst klangligt lydbillede i rock $\mathrm{n}$ roll. Det består i den designede massifisering gennem den samtidige ophobning af det tilnærmelsesvist samme.

Når man taler om Spectors massifiserede lydflade som en mur af lyd, understreger man ikke blot, at lyden er flad. Man siger samtidig også, at der i kraft af lydens fladekarakter opstilles en grænse, som lukker det lyttende subjekt inde eller ude. Muren er, på grund af dens kraftige kohærens og stoflige fortætning, umiddelbart uigennemtrængelig. Men samtidig er muren ikke blot en grænse. Den udgør samtidig også det, der afgrænser sig. På samme måde som en kant alene udgøres af sit stof og samtidig skærer en grænse i rummet mellem dette stof og noget, der er forskelligt herfra, placerer muren sig som en grænse i rummet netop i kraft af sin massive fortætning. Den træder alene frem for subjektet i og som en massiv kant, en overflade i to dimensioner af et helt udfyldt andet rum.

Massifiseringen bidrager altså i sig selv til en større grad af overfladiskhed. På den måde er Spectors lydflade i mange henseender den direkte modsætning til det dybe klangrum, sådan som man for eksempel kender det fra jazzens stadig forbløffende rumlige indspilninger fra sidste del af 50 erne eller fra Brian Enos senere am-

97 Jf. Moorefield I2. Ifølge Jack Nietzsche, Spectors tætte samarbejdspartner og arrangør og leder af Spectors foretrukne studiegruppe, The Wrecking Crew, indebar en typisk studiesession med Spector bl.a.: "four keayboards... a grand piano, a Wurlitzer electric piano, a tack piano, and a harpsichord... three acoustic guitars, three basses (acoustic, electric, and a six-string Danelectro bass), electric guitar, three or four percussionists, a drummer" (citeret fra Zak 78) For en mere indgående beskrivelse af Spectors samarbejde med The Wrecking Crew og ophobningen af musikere i studiet fra og med Zip-A-Dee-Doo-Dah, se også Brown Ioo-I05. 
biente plader. Der er intet hul i muren, hvorigennem subjektet kan lytte sig ind til et andet rum imellem eller bagved lydens kant; noget tomt eller udækket, der kan fungere som udgangspunkt for aftegningen af andre rumligheder. Af samme grund spiller spatialiseringen, den specifikt rumlige relation mellem enkeltlydene, ingen større rolle i opbygningen af Spectors lydflader. Lydene udfylder så at sige det samme punkt. Sampling- og ophobningsteknikkerne medfører ikke blot, at intet i lydfladen træder mere frem end noget andet og tager særlig plads i opmærksomheden, men også at intet træder mere tilbage og giver plads. Ophobningen af identiske lydfragmenter på samme tid og sted betyder således, at alle elementer i lytningen rumligt nærmer sig samme fornemmede afstand, uafhængigt af deres virtuelle rumtidslige placering i lydfeltet, dvs. uafhængigt af deres klanglige kvaliteter som kraftig/svag, kort/lang, hård/blød etc. De udgør et eneste fast plan, en blok af lyd.

Det er i dette forhold, at vi finder grunden til Spectors stædige fastholdelse af mono-optagelsen også i mange år efter, at stereo-optagelse var blevet almindelig. Hvor stereo har en højere loyalitet overfor den virkelighed som den gengiver (mediering), har mono i sit udgangspunkt i stedet umiddelbart en højere loyalitet over for den teknologi, hvorigennem lydfladen materialiserer sig (medialisering). Men spørgsmålet om graden af realisme har dog næppe haft nogen relevans for Spectors forkærlighed for mono. Der er nok snarere tale om den rent æstetiske begrundelse, at massifiseringen i højere grad ligger indlejret i selve mono-optagelsen som teknologisk praksis. I mono spaltes lydene ikke ud og tildeles specifikke pladser i en horisontal lydflade, men fortættes inden for samme komprimerede ramme. Højttaleren - for den tidlige Spectors vedkommende vil det primært sige jukeboxenes og AM-radioernes højttalere - er en afgrænset lydboks, inden for hvis ramme lydene ikke fordeler sig horisontalt, men hober sig op i ligelig akkumulation..$^{8}$

En anden af Spectors praksisser, den berømte one mike over everything-teknik, som han ligesom ophobningsteknikken første gang eksperimenterede med under optagelserne til Zip-A-Dee-Doo-Dah, står i direkte relation til fastholdelsen af mono og kan ses som endnu et udtryk for samme ønske om massiv komprimering af lydfladen. Spectors for samtiden radikale mangfoldiggørelse af lydkilderne foran en enkelt mikrofon betyder naturligvis ikke blot endnu mere lyd. Den betyder også endnu mindre virtuel plads til hver enkelt lyd at fordele sig på i det indsnævrede klangfelt. Med kun en enkelt mikrofon registreres samtlige lyde i rummet - i modsætning til ved menneskets to ører som stereo-teknologien mimer - til et eneste punkt og vil derfor ikke efterfølgende give lytterne foran jukeboxen mulighed for $\mathrm{i}$ samme grad at skabe illusionen om virkelighedens tre dimensioner som noget, der skulle ligge indlejret i selve lydfladen. På den måde fremstår mono-fonogrammet

98 Zak drager en lignende konklusion: "Indeed, the 'wall of sound' is one thick textural mass, many of whose constituent parts are indistinct to the ear. Spector's love for the impressionistic effect created by the overall sonic tapestry was one of the reasons he insisted that monaural records were superior to stereo. With no spatial separation between the sounds on the record, they all merged into one massive, opulent texture from which only the vocals and the most salient musical gestures stood out." (88) 
i denne henseende ikke blot mere to-dimensionelt og overfladisk, men også mere konstrueret, mere optaget, mere kunstigt. Mono formår, i modsætning til stereo, noget, som mennesket ikke selv gør uden brug af teknologien, nemlig at afgrænse det fulde lydrum til et enkelt, snævert område, hvori lydene fortættes.

\section{Kunstighed og syntetisering}

Den lokale massifisering afvikler ikke blot den enkelte lyds unikke status i lydbilledet. I tæt forbindelse hermed medfører den samtidig en afvikling af lydenes antropomorfe træk, det vil sige deres evne til at pege på en bagvedliggende menneskelighed. Antropomorfismen, som i større eller mindre grad vil kendetegne alle 'akustisk' spillede instrumenter - og som stadig i dag udgør et kernepunkt i forbindelsen mellem det musikalske og det ekspressive - udviskes proportionelt med en stigende grad af mangfoldiggørelse. Det er en af de helt centrale sider af designet, som det kommer til udtryk hos Spector såvel som i vore dages studieproduktioner, at det gennem en objektivisering af de musikalske enkeltelementer i større eller mindre grad reducerer lydenes antropomorfe træk ved at sløre eller helt løsrive dem fra deres menneskelige ophav. At påbegynde designet af de teknisk frembragte lyde er at bidrage til deres klanglige transformation fra menneskelignende udtryksformer til egentlige lydobjekter, at placere lydene på samme betydningsmæssige niveau som andre objekter i den mundane, akustiske verden.

Af samme grund bidrager lydenes fortættede massifisering ikke blot til forfladigelse, men også til en kraftigere medialisering af lydfladen. Dette ses for eksempel i den, i denne henseende, fundamentale forskel mellem solo og unisoni. En musikalsk figur spillet eller sunget af mange unisont har i den forstand en større grad af medialitet over sig end den samme figur spillet eller afsunget solo af blot et enkelt instrument eller en enkelt sangstemme. Når den samme tone klinger fra to ens instrumenter samtidig, vil det karakteristiske ved produktet ikke så meget være forstærkningen af den enkelte tone gennem kopieret mangfoldiggørelse. Det prægnante ligger snarere i det ellers indlysende forhold, at lydene vil interferere og danne en ny tonestruktur. Afhængigt af graden af de enkelte lydkilders formelle lighed vil det emergente resultat, der høres i fordoblingen, ligge tættere eller fjernere fra de enkelte oprindelige lydkilders kvalitative identiteter. Men med fordoblingen er den proces påbegyndt, der opløser den afgrænsede lydidentitets reallydlige forankring. De enkelte lydobjekters opløsning i massen betyder samtidig en opløsning af deres referentielle egenskaber i forhold til en verden udenfor dem selv. Den nye og fortættede masselyd høres måske som en afgrænset lyd, som et nyt objekt, men den henviser ikke, i samme grad som den enkelte lyd fra solo-instrumentet gør det, til et bagvedliggende udspring i den konkrete verden før den tekniske formation. Den udfolder sig æstetisk set som løsrevet fra sit klanglige ophav, sin kilde. Det betyder, at den massifiserede lyd ikke rummer en samlet kompleks henvisning, ad mangfoldige spor, til hver enkelt af sine lydkilder. Den henviser alene til sig selv som masse, til sig selv som den konstruerede samling af 'de mange'. 
Når Spector benytter sig af gentagelser af bestemte figurers kvaliteter med, så vidt muligt, maskinel præcision og på alle parametre, ligger resultatet af den lydlige flerdobling tilsvarende tæt på hver af de enkelte ophobede figurer, sådan som disse ville have lydt solo før fortætningen. Men på trods heraf træder massifiseringen alligevel frem og får den markante effekt, der i så gennemgribende et omfang præger Spectors lydflader, ved netop at producere en ny, objektiviseret og mere anonym lyd. Af den grund er Spectors lydflader ikke blot mere objektive, overfladiske og kunstige, men fremstår også med en mere konkret og materiel karakter. Medialiseringseffekten af den ophobede lyd er i udpræget grad en stoflig effekt. Den udfolder sig ikke blot i kraft af, men som den fortættede materie. Det er i særlig grad denne medialiserende virkning af massifiseringen, der placerer Spector centralt $i$ en periode i musikhistorien, hvor omslaget i sensibiliteten hen imod designet begynder at gøre nogle af sine første store bevægelser. Vi er her vidne til et skift $i$ opfattelsen af musikkens materiale fra musikalske lyde, det allerede musikaliserede materiale, og hen imod musikalsk anvendte lyde. Fra lyde, der lyder som oprindeligt tilvejebragt og fremført inden for en allerede musikalsk kontekst, og mod lyde, der lyder som konkrete lydobjekter, og som først senere er blevet tildelt en egentlig musikalsk kvalitet med det designende indgreb. Spector indlejrede massifiseringen som en æstetisk kvalitet ved den måde, den fortættede lyd fremtræder på i den medialiserede virkelighed. Og samtidig hermed blev musikkens fænomenale fundament forskudt. Musikkens 'oprindelse' flyttede sig.99

Man skal af denne grund ikke forveksle Spectors design med den konkretisering af det musikalske materiale som fandt sted i I950'ernes franske musique concrète, hvor den objektive verdens konkrete lyde fandt en af sine første, udpræget fonogrammatiske anvendelser. Spectors materialisering og konkretisering udfolder sig, om man så må sige, på en både mere subtil og mere kompleks måde. Mangfoldiggørelse af de enkelte stemmer bidrager hos Spector, som i musique concrète, til konkretisering og materialisering, eller hvad man med musique concrète-pioneren Pierre Schaeffer kunne kalde en akusmatisering, af lydfladen. ${ }^{\text {Ioo }}$ Men - og heri ligger den afgørende forskel mellem Spector og musique concrète - Spectors akusmatisering finder på paradoksal vis sted inden for den allerede musikalske kontekst, som hans design samtidig bryder med. Spector bryder ikke med den musikalske begivenhed (komposition og opførelse) for at skabe konkret musik bestående af den objektive verdens medialt

99 Milner taler således om, hvordan Spector "consciously used the studio to bring to life a specific sound that had no counterpart in reality. Not only did Spector not care about high fidelity, he actively courted high infidelity. On of the guiding principles of his wall of sound was that no individual instrument should be discernible, except for the drums." (153)

Ioo På baggrund af en anekdote om Pythagoras, der forelæste for sine tilhørere (akousmatikoi) bag en skærm, så de bedst muligt kunne koncentrere sig om det talte ord, definerede Schaeffer akusmatisk lyd som den lyd, man hører uden at kunne se den hændelse, som forårsager lyden. (Schaeffer 9I) Selvom begrebet derved i princippet dækker alle de lyde, som opstår uden for synsfeltet, anvendes det, af såvel Schaeffer som efterfølgende musikteoretikere, hovedsageligt om forhold ved den tekniske reproduktion, hvorigennem man søger at fremhæve den reproducerede lyds iboende klanglige og formelle egenskaber ved at tildække lydens fænomenale oprindelse i medieeksterne realiteter. 
løsrevne og akusmatisk tilslørede lyde. Han foretager en akusmatisering af lydfladen på baggrund af det allerede musikalske. Han konstruerer ud fra det musikalske en ny virtuel realitet, inden for hvilken lydfladen vokser frem som konkret, medialiseret masse. Denne medialiserede realitet er ikke virkeligheden i sin rå og uformidlede, reallydlige form endsige virkeligheden reproduceret. Og den er ikke virkelighedens modsætning i den rene, abstrakte kunstighed. Den er musikalsk virkelighed som konkret, materialiseret design.

Dette konkrete design kommer med stor tydelighed til udtryk i anden væsentlig teknik, som Spector også introducerer i sine tidlige produktioner: konstruktionen af en ny lydenhed gennem sammenblandingen af forskellige lydobjekter. Et af de klareste eksempler på dette finder man i Spectors design af det berømte lilletrommeslag på Be My Baby. Denne afgrænsede lyd markerer hvert 4-slag i de indledende takter og fortsætter stort set uændret nummeret igennem, nu dog kun på hvert andet 4-slag. Foruden et almindeligt lilletrommeslag, flerdoblet og tilsat en kraftig rumklang, består lyden yderligere af en række andre tilsatte lyde: claves, tamburin, håndklap og kastagnetter. Den særlige effekt ved denne lyd er at den, selvom den måske fungerer musikalsk som lilletrommeslag i konventionel forstand, ikke længere lyder som en lilletromme, men har fået en unik og netop sammensat klang. Lilletrommeslaget er ikke længere et lilletrommeslag, der henviser til sit instrument, men i stedet blevet til lilletrommeslaget på Be My Baby'. Spector konstruerer med andre ord - in recording og uden brug af multitracking en ny og essentielt fonogrammatisk klang-enhed, et lydobjekt, der præcist er afstemt til optagelse gennem mixet af forskelle.

Denne teknik har klare paralleller til moderne, analoge klangkonstruktioner og digital processering, der gennem detaljeret kombination samler forskellige lydenheder til et nyt objekt. Samtidig knytter teknikken mere generelt an til idéen i den nyere pladeindustri om mixet som en opbygning af en på samme tid sammenhængende og sammenblandet musikalsk lydflade. Men i modsætning til de nyere metoder foretager Spector hovedsageligt sin lydkombination før enhver teknologisk efterbearbejdelse og redigering. Der er derfor ingen større teknisk forskel mellem Spectors sammenblandingsmetode og datidens mere traditionelle arrangementsmetoder. ${ }^{\mathrm{IOI}}$ Men rent æstetisk er forskellen betydelig, idet den sammenblandede lyd hos Spector ikke udfolder sig i oplevelsen som en mere eller mindre tydelig kombination af forskellige samtidigt klingende stemmer, hver med deres egen unikke lyd - altså med en mere eller mindre tydelig sammenblandingseffekt som resultat. Den høres alene og fuldt ud som en ny, syntetisk konstrueret enhed, der er blevet designet for optagelse gennem en for lytteren uigennemskuelig

IOI Man kan i den henseende se væsentlige paralleller mellem Spector og den teknik, hvor forskellige lyde organiseres i en samlet akustisk enhed, som den franske komponist Edgard Varèse udviklede i årtierne før. Varèse fokuserede dog på akustiske og elektro-akustiske klangkontruktioner, ikke på produktionen af specifikt fonogrammatiske enheder. For en diskussion af den musikalske lydmasse-komposition i det 20. århundrede hos Varèse, Iannis Xenakis, Györgi Ligeti etc. behandlet i relation til massefænomener i almindelighed, se Hjortkjær, Den musikalske masse. 
og umærkelig ophobning af forskelle. Af den grund kan Spectors lyddesign siges at have mere til fælles med teknikken bag den moderne synthesizer, hvor selve sammenblandingen ligeledes sker i udgangspunktet for lydproduktionen. Den syntetiske sammenblanding høres her ikke som en isoleret kvalitet ved den enkelte lyd - den lyder ikke mere sammenblandet end andre lyddannelser. Men det er, i synthesizeren endnu mere end hos Spector, alene blandingen, der giver hver enkelt lyds sine selvstændige klangegenskaber. Den syntetiske lyd er alene et resultat af det interferentielle møde mellem forskellige partikulære lyddannelser, der opløses fuldt ud i en ny medialiseret enhed.

\section{Lydspor}

Foruden den populære mur-metafor kan man - typisk mere populært - høre Spectors lyd beskrevet som et i særlig grad mudret lydbillede. ${ }^{\mathrm{IO2}}$ Men betegnelsen er ikke velvalgt. Den er så at sige for vandig. Den henviser til en genstand, der er for inkonsistent, for let at trænge igennem. Spectors lyd er ikke blot overfladisk som muren; den er også, ligesom den, i udpræget grad uigennemtrængelig. Til trods for den manglende begrebslige præcision peger mudder-metaforen dog på en helt central kvalitet ved Spectors design. Uigennemtrængeligheden er det fortættede resultat af en vertikal stabling af lydobjekter i et komprimeret punkt. Men dette punkt er samtidig blevet gjort til genstand for en designproces, der breder punktet ud igen ved at afrunde lydmassens kant. Muren er med andre ord så at sige en blød mur. Ikke en hård mur med et blødt, mudret lag på overfladen, men en mur konstrueret $\mathrm{i}$ et blødt materiale. Og dog mister den ikke derved sin koncentrerede flade-karakter, sin høje grad af sammenhængskraft. Blødagtigheden får ikke murens enkeltdele til at spalte sig ud fra hinanden igen, men bidrager tværtimod kun til en desto kraftigere samling og fortætning. Den tætte masse, der møder lytteren ved højttalerens kant, er på samme tid blød og konsistent; som en fast, gennemæltet dej.

Det er Spectors for samtiden yderst massive brug af ekkorum og rumklang, der mere end noget andet har denne blødgørende indvirkning på lydmassen.103 Generelt bruges betegnelsen hårde klange typisk om de klange, der træder frem $i$ lytningen med en relativt skarpt kantet envelope - det vil sige med kort attack og kort release. ${ }^{104}$ I modsætning hertil har såkaldt bløde klange en mere afrundet envelope med længere attack og længere release. Rent teknisk har rumklang ingen indflydelse på en lyds envelope, men dens effekt svarer æstetisk set til en blødgørelse

IO2 Beskrivelsen af Spetors lyd som mudret kan observeres i talrige anmeldelser, journalistiske musikartikler og andre ikke-akademiske tekster om Spector. Zak anvender en lignende betegnelse, når han beskriver Spectors lyd som "a kind of musical soup". (78)

I03 For en beskrivelse af Spectors intense brug af ekkorum som et helt centralt element $i$ hans wall of sound, se Zak 77.

I04 En lyds envelope beskrives inden for lydteknologien typisk ud fra den firdelte struktur Attack-Decay-SustainRelease (ADSR), hvor attack og release i denne sammenhæn er de væsentligste. Attack betegner den tid, det tager en lyd at nå sit styrkemæssige højdepunkt. Release betegner den tid, det tager en lyd at klinge ud fra sit normale styrkemæssige leje (sustain-niveauet). 
af lyden i samme forstand. Rumklangen fjerner markeringen af lydens formelle kant ved at lægge en tæt hinde af svagere gentagelser omkring den, der kopierer lyden fremad i tid og udad i det virtuelle rums tre dimensioner. Det er på den måde, at rumklangen kan siges at udbrede den enkelte lyd.

Spector benyttede ofte rumklang som distinkt effekt på enkelte, lokalt udfoldede lydobjekter. Men det er den massive anvendelse af rumklangseffekter i optagelsen og på den samlede lydflade - realiseret ved henholdsvis at placere mikrofonen i relativt lang afstand fra lydkilderne og ved senere i processen at køre master-signalet igennem ekkorum - der giver Spectors lyd den særlige blødhed, som tidens teenagere med tilfredshed forvekslede med en helt ny form for klanglig dybde foran transistorradioerne og ude ved jukeboxene. Men rumklangens massifisering tilfører ikke lydfladen en ny form for illusorisk dybde. Spectors lyd er stadig fundamentalt overfladisk. Den illusoriske oplevelse af dybde skyldes snarere den mere subtile fornemmelse af blødhed. Blødhedseffekten er netop ikke et resultat af en større distance mellem de enkelte lyde i det samlede klangrum eller en større og mere dybdeskabende adskillelse af forgrunds- og baggrunds-planerne, men i stedet det nøjagtigt modsatte: en mere markant samling af de enkelte lyde inden for det samme plan i det virtuelle klangrum. Rumklangen skaber ikke mere, men derimod mindre rum til hver enkelt lyd. Den udjævner og blødgør fladen ved at slibe skarpheden af de lokale fremspring og derigennem fratage hver enkelt lyd muligheden for at skille sig ud i blandt de andre, at blive et salient fixpunkt for lytteren, der som figur står ud i feltet på de andre lydes grund.

Blødgørelse ved rumklang betyder altså på paradoksal vis en kraftigere planering af lydstrukturen på grund af effektens dehierarkiserende indvirkning. Og samtidig tilfører rumklang en større konsistens til lydfladen. Afrundingen af dens forskellige elementer lader i udpræget grad disse smelte sammen i syntetisk enhed. Spectors produktion af en enhedslig lydflade er altså til dels en effekt af det blødgørende design. Men enhedsliggørelsen er samtidig i væsentlig grad begrundet $i$ lydfladens egen medialisering, hvor selve optagelsesmomentet har indlejret sig i hver klanglig detalje med virkningen af den distant placerede, enlige mikrofons samlende registrering af lydbegivenhederne i studiet. Enhedskarakteren af Spectors lydflader er en æstetisk effekt af det allerede medialiserede. Den medfører ikke blot en endelig opløsning af det musikalske klangrum som et sammensat akustisk rum bestående af forskellige instrumenter $i$ arrangeret kombination. Den skaber samtidig en ny måde at klinge på, der subtilt, men stringent, peger tilbage på det oprindelige medialiseringsmoment. Det, at lydene er blevet optaget og teknologisk medieret i fonogrammet, giver dem altså ikke blot en materiel kvalitet af lydteknologi og lydlig medialisering. Medialiseringen er blevet en egentlig formel kvalitet ved dem som produkter designet for fonogrammet. Den er blevet fundamentalt indlejret $\mathrm{i}$ deres måde at samle sig på for lytteren, i deres måde at fremtræde på og forme sig som en enhed i oplevelsen.

Gennem denne substantielle medialisering har Spector med andre ord fuldt ud fjernet lydfladen fra dens akustiske og antropomorft musikalske oprindelse og 
samlet den til et egentligt lydspor, et soundtrack. Lydsporet er det, der opstår, når medialiserede lyde forener sig i en konsistent medialiseret enhed, og den særlige lydsporskarakter ligger netop i denne samtidige kombination af medialisering og enhedsliggørelse. På paradoksal vis er det dog samtidig netop denne kvalitet af lydspor, som tenderer imod igen at dele lydfladen på de tidlige Spector-produktioner. Naturligvis adskiller denne deling sig radikalt fra delingerne i det akustiske orkester, hvor de forskellige lydkilder i højere grad skiller den samlede orkesterklang i hver deres eget klangfelt. Spectors deling manifesterer sig snarere som en udspaltning af den medialiserede klangenhed $i$ to fra hinanden tydeligt løsrevne spor, to adskilte blokke af lyd, der henholdsvis trækker sig frem og tilbage i det virtuelle lydfelt. Sammen danner de to spor en ny for- og baggrundsstruktur i den samlede lydflade i form af det, man inden for senere lydproduktion efterhånden begyndte at betegne lead- og backing-tracks. Spectors massive samling af klangene til en blød, medialiseret enhed er samtidig den væsentligste faktor for den nye etablering af klangrummet som en spaltet flade af separate lydspor. Idéen om en for- og baggrund i musikken har måske eksisteret $\mathrm{i}$ århundreder, i det mindste implicit i form af en adskillelse mellem fremtrædende og mindre fremtrædende (akkompagnerende) dele. Men fornemmelsen for lyden som udspaltet i tracks opstår først i det øjeblik, hvor designet har syntetiseret lydene og medialiseringen er blevet gjort til en substantiel egenskab ved deres fremtrædelse. Først med den medialiserende syntese kan en ny fænomenal afgrænsning finde sted i klangfeltet i form af den fonogrammatiske udspaltning af enkeltstående, uforankrede og ubrydelige blokke af lyd.

\section{Poplyd}

Sammenlignet med backing-tracket, der udgør substansen i Spectors lydflade, kan meget umiddelbart synes anderledes i forhold til den måde, lead-tracket fremtræder på i det samlede lydfelt. Lead-tracket hos Spector består typisk alene af forsangerindens lead-vokal, eventuelt i unison med de andre sangerinder. Blandt andet ved at have fået tilført mindre rumklang lægger lead-stemmerne sig relativt meget længere fremme i lydbilledet end det massive backing-track, som fylder resten af den tætte lydflade. Ved på den måde at placere sig $i$ et andet og umiddelbart mindre designet og medialiseret rum kan girl group-sangerindernes stemmer derfor synes at antyde en rest af førdesignet menneskelighed i en ellers markant afantropomorfiseret og gennemmedialiseret lydflade.

Det er i denne adskillelse af lydfladen i to sideløbende, men kvalitativt forskellige spor, at Spector udgør et væsentligt historisk udgangspunkt for udviklingen af en egentlig poplyd. ${ }^{\text {Ios }}$ Pop som lydæstetisk kategori finder netop, også i dag, et af sine væsentligste kendetegn i udspaltningen af en gennemmedialiseret og gennemdesignet lydflade i to overfladiske enheder, der sammen kan udspille en konfrontation mellem det standardiserede og det individuelle, mellem det objektive og det sub-

I05 De standardiserede strukturer og melodiske konventioner, som popmusikken tager til sig, har selvsagt eksisteret i mere oprindelige former længe før Spector. 
jektive. Den poppede lydflade fremtræder altid med et essentielt præg af designede spor. Men den bevarer samtidig en rest af det førdesignede, det unikke moment. Spector tildeler dette subjektive moment sin plads i lead-tracket, men indhyller det samtidig $i$ en designet baggrund af tæt, objektiviseret og medialiseret lydmasse. Da girl group-lytteren Andy Warhol - i de samme år som Spector tidlige produktioner fyldte radiofladen - bevægede sig fra den rent kommercielle, grafiske designindustri og til at skabe pop som designet kunst, skete der et tilsvarende omslag inden for billedkunsten. På samme måde som Spectors spinkle pigestemmer pegede tilbage på en voldsom subjektivitet inkarneret ved teenagepigens spirende lyster (Not Too Young to Get Married; Da Doo Ron Ron; Be My Baby), kom den poppede effekt i Warhols billeder tilsvarende til udtryk i modstillingen af krystalklare, ikonisk voldsomme forside -billeder på en konceptuelt gennemdesignet masse-baggrund af serielt ophobede kopieringer. Af samme grund fremstår individualiteten hos både Spector og Warhol blot som en spinkel og skrøbelig rest i massen, et flygtigt minde, der måske trækker små tråde tilbage i tiden, men ikke længere er kvalitativt tilstedeværende som fuldt aktualiseret moment. I poppen har medialiseringen altid allerede slået igennem, også i forgrundens unikke individualitet, og formelt stemplet fænomenerne med en ubetinget massekarakter.

I sin analyse af 20 ernes populærmusik fremhævede Theodor W. Adorno en karakter af pseudo-individualitet som et af denne musiks væsentligste kendetegn. Pseudo-individualiteten kom ifølge Adorno til udtryk i et subtilt, men gennemgribende krav om frembringelsen af tegn på det unikke moment i den ellers gennemstandardiserede musikalske struktur. Adorno diskuterede dog alene fænomenet i relation til komposition, arrangement og til dels opførelse. (Jf. Adorno, "On Popular Music") Med Spectors spaltede flader får det pseudo-individuelle betydning i direkte relation til det lydlige materiale og dets fremtrædelsesform. Pigestemmernes spinkle klang i forgrunden har allerede mistet deres entydige oprindelse $\mathrm{i}$ individualiteternes virkelighed udenfor designet, så snart baggrundens fortætning i det medialiserede lydspor udfolder sig og begynder at omgive dem. Ikke på grund af den teknologiske reproduktion, som allerede i girl group-æraen ikke længere kunne chokere publikum ved sin adskillelse af verdenerne, men fordi stemmens lydlige grund er så radikalt syntetiseret og designet. Og det er netop sådan Spectors pigestemmer lyder: som forladte og fortabte individualiteter i et massivt lag af grundløs medialitet. Den klanglige kilde til popmusikkens ofte fremhævede drømmende eller eskapistiske karakter kan til dels også findes i dette forhold: $\mathrm{i}$ forskydningen af en isoleret subjektivitet ind i kunstighedens verden, hvad enten denne verden er hypervirkelig og distant fascinerende, som den 'medieverden', den medierede og medialiserede popstjerne henviser til, eller den alene toner frem i kunstighedens konkrete, lydlige moment.

Med Spectors adskillelse af lydfladen og pigestemmernes forskudte isolation har den skrøbelighed og tvetydige melankoli, som ofte kendetegner popnummeret midt i alle dens løfter om lykke, samtidig fået et æstetisk udtryk i den konkrete lydflade og dennes immanente organisering. Pigevokalens udtryk er - som i den 
enkelte teenagers påtrængende behov - momentant indhyllet i en specifik og radikalt subjektiv alvor og fremstår dog på samme tid, og af samme grund, så simpelt, let og banalt, så generelt, standardiseret og gentaget, så grundløst overfladisk. Man har set denne dialektik - mellem fylde og tomhed, mellem dybde og flade, mellem individualitet og standardisering - udfolde sig i popsangen i talrige populære sange før og efter Spector i form af subtile sidestillinger af bekymring og lethed. Men Spector skriver som en af de første splittelsen ned i selve lydens formelle og materielle udfoldelse. Ved at isolere pigestemmen fra den omkringliggende lydmasse og placere den løsrevet forrest i fladen, lige ud for hver enkelt teenager ophobet foran jukeboxens højttaler, skaber han et helt konkret potentiale for et personligt forhold, en én til én-relation, mellem lead-sangerindens isolerede klang og hendes lytter. Når Adorno i 1938 talte om en "likvidering af individualiteten" som det egentlige resultat af den "nye musikalske tilstand", så havde han på samme tid ret og uret. (Adorno, "Über den Fetischcharakter" I5f) Han havde uret, fordi individualiteten ikke blev likvideret med den teknologiske masseproduktion og varegørelsen af musikken; ret, fordi individualiteten optog sin egen modsætning, masserne, i sig. Der er med introduktionen af den gennemdesignede lydflade ikke tale om en afvikling af musikalsk intimitet, men snarere om et markant omslag i dens kulturhistorie. Dette omslag fostrede samtidig et af massekulturens store paradokser: at hver enkelt konsument tildeles muligheden for på samme tid at have standardiserede, masseproducerede og individuelle, intime oplevelser. Med den syntetiske lydflades produktion skabes potentialet for udfoldelsen af en på samme tid distanceret og pågående, gennemmedialiseret intimitet.

Men samtidig med at Spector som en af de første fuldt ud designede effekten af adskilte lydspor i musikken, var han også en af dem, der mest markant påbegyndte en opløsning af forskellene mellem dem igen. Et af de mest karakteristiske og oftest fremhævede træk ved Spectors wall of sound er netop den umiskendelige og for samtiden hidtil uhørte tilnærmelse mellem figur og grund. Lead-vokalen skiller sig måske rent klangligt klart ud fra resten af lydfladen i kraft af det spaltede design. Men sammenlignet med andre produktioner fra første del af 60 erne gør den det samtidig uhørt lidt. Spector "begravede frontvokalen, og han kan ikke lade vere med at gøre det”, har Spectors medkomponist på mange af de største hits, Jeff Barry, senere beskrevet det; frontvokalen synker længere og længere tilbage, og for mig er det, han [Spector] siger, at det er ikke sangen, jeg skrev med Jeff og Ellie, det er ikke sangen - lyt til strygerne. Jeg vil have flere musikere, det er mig, lyt til den baslyd'." (Barry i Williams II4)

Massifiseringen skabte et fladt og spaltet design. Men det var samtidig massifiseringen, der resulterede i en tilnærmelse mellem for- og baggrund. Denne tilnærmelse var til dels foranstaltet ved den massive ophobning af lydkilderne i fladen, til dels ved den massive brug af global rumklang. Rumklangen samler ikke blot lydene i sporet $i$ en tæt lydenhed, men formindsker samtidig globalt den virtuelle afstand mellem figuren og grunden. Spector skaber på den måde en lyd, der på samme tid opleves overraskende todelt i forgrund og baggrund og, for samtiden lige så over- 
raskende, lader sig høre som en samlet og uhyre fortættet flade af massifiseret lyd og netop ikke som et rum delt i to, netop ikke som et dybt og spaltet felt. Det spaltede og det udelte er to aspekter af det samme design.

Det er med indlejringen af en sådan dobbelthed i selve lydens materie og potentielle fremtrædelsesform, at det lykkedes Spector at skabe en popmusik, der passede særdeles godt til datidens teknologiske anordninger og kulturelle tendenser umiddelbart før hi-fi-stereo og rockmusik. Og samtidig placerede det samme design ham som en af de væsentligste inspirationskilder for senere eksperimentelle støjrockbands som The Jesus and Mary Chain og My Bloody Valentine og relaterede bands fra 90 erne såsom Chapterhouse og Moose, hvis vigtigste fælles kendetegn netop var den musikalske opløsning af for- og baggrund i en samlet og ofte støjende flade af lyd. I transistorradioerne fortættes den flade lyd til en komprimeret og blødgjort pop, der synes at fylde monohøjttaleren helt ud. Og samtidig stiller Spectors lyd en massiv og uigennemtrængelig grænse op for lytteren, der umiddelbart kunne synes popmusikken fremmed. Pop var for Spector ikke bare populære hits for den voksende skare af teenagere i begyndelsen af 60 erne. Det var også den mest velegnede platform for seriøse, musikalske eksperimenter. Med en betegnelse, der rummer denne modsætning i sig, talte Spector efter sigende selv om sin musik som "little symphonies for the kids". (Willams 77) Girl group-sangerindernes bevidst barnagtige pigestemmers umiddelbarhed blander sig med den professionelle grundighed, hvormed den massive lydflade, de indhylles i, er blevet designet.

Muligheden for teenage-oprigtig intimitet, umiddelbarhed og spontanitet tilbudt $i$ et gennemmedialiseret og gennemdesignet masseprodukt var den lydlige popdialektik, Spector introducerede på markedet. Samtidig udgjorde hans hits, med deres massifiserede og dehierarkiserede flade, begyndelsen til en ny organisering af lydene. Denne nye organisering manifesterede på mange måder den spirende kulturelle ændring i musikopfattelsen hen imod designet, som i dag sætter et fundamentalt præg på den globale lydkultur. I dag tænkes designet ikke længere som et vedhæng til en mere fundamental og oprindelig form, hverken i den professionelle musikproduktion, som Spector pionerede, eller i lydkulturen generelt. Den uforankrede medialitets materie er blevet et naturligt udgangspunkt for lydenes tilblivelse.

For eksempel accepteres en reproduceret stemme, der ikke har gennemgået en designproces, ikke længere umiddelbart som mere realistisk og naturligt forankret i den førmediale verden end den samme stemme, når den er blevet designet. Tværtimod virker den reproducerede stemme, der fremtræder i sin ubehandlede gengivelse - det vil sige før enhver form for massifisering - efterhånden mere kunstig, unaturligt fragmenteret og uforankret end dens medialiserede variant, der indsætter sig i mediet. Denne fornemmelse af det manglende designs uforankrethed beror naturligvis ikke længere på en fænomenal spænding mellem den akustiske stemme og dens tekniske reproduktion, sådan som mange historiske beretninger kan fortælle at det skete i lydoptagelsens første år, men netop på den utilstrækkelige grad af medialisering. På samme måde som ansigtssminken i tv-studiet er blevet et helt 
nødvendigt middel til gennem massifisering at tilføre huden på de medvirkende en tilstrækkelig grad af medialiseret naturlighed, som deres hud ikke i sig selv kan levere, tilføres medierede stemmer i dagens lydbillede ofte diskret designede virtuelle rum og massificeret fylde for at lytterne ikke skal blive forstyrret af deres ellers åbenlyse mediering og i stedet indsætte mediet som lydenes altoverskyggende, æstetiske oprindelse. Noget tilsvarende gør sig gældende i forbindelse med diverse elektriske instrumenter. Det gælder ikke mindst den elektriske guitarlyd, som den har udviklet sig siden midten af 1960'erne. Umedialiseret fremtræder elguitarens lyd typisk aldeles ufærdig og synes først at etablere sin egen lyd med hjælp fra diverse konkret massifiserende effekter (chorus, rumklang, kompressor, distortion, tremolo osv.). ${ }^{\text {ro6 }}$ Den umedialiserede lyd udgør måske et potentiale for det musikalske design, men den realiserer sig først fuldt ud som æstetisk produkt i det mediale møde med effekterne. Den uproducerede lyd bliver først til i mediet, når den fortætter sig i en form for design.

\section{LITTERATURLISTE}

Adorno, Theodor W. "On Popular Music”. Zeitschrift für Sozialforschung (I94I): I7-48.

Adorno, Theodor W. "Über den Fetischcharakter in der Musik und die Regression des Hörens”.

Dissonanzen. Göttingen: Vendenhoeck \& Ruprecht, 1958. 9-45.

Auslander, Philip. Liveness: Performance in a Mediatized Culture. New York: Routledge, I999.

Baudrillard, Jean. For a Critique of the Political Economy of the Sign. St. Louis, Mo.: Telos Press, I98I.

Benjamin, Walter. "Das Kunstwerk im Zeitalter seiner technischen Reproduzierbarkeit". Gesammelte

Schriften I, Frankfurt a.M.: Suhrkamp, 1980. 47I-508.

Brown, Mick. Tearing Down the Wall of Sound: The Rise and Fall of Phil Spector. New York: Knopf, 2007.

http://www.amazon.com/Tearing-Down-Wall-Sound-Spector/dp/I400042194/ref=pd_

sim_b_28Chanan, Michael.http://www.amazon.com/Repeated-Takes-History-Recording-Effects/

dp/r859840I24/ref=pd_bxgy_b_text_c Repeated Takes: A Short History of Recording and Its Effects on

Music. London: Verso, I995.

Foster, Hal. The Return of the Real. Cambridge, Mass.: MIT Press, I996.

Fremer, Michael. "Climbing 'The Wall of Sound' With Gold Star Recording Studios Co-Founder

Stan Ross. Michael Fremer's Music Angle. I. maj 2009 <http://www.musicangle.com/feat.

php?id=I22>.

Io6 Hovedparten af de analoge og digitale effektmaskiner, som anvendes i moderne musikproduktion og lyddesign, kan netop ses som forskellige former for massifiserende syntetiseringer af lydmaterialet: Distortion, overdrive, fuzz og lignende forvrængningseffekter manipulerer således eksempelvis materialet ved på forskellig vis at klippe lydens bølgeform til mere kantede svingningsforløb, hvormed lyden fortættes i en mere udjævnet form. Tremolo og kompression manipulerer på forskellig vis lydbølgens amplitude, så der skabes et mere samlet og standardiseret svingningsforløb. Filtrering syntetiserer og koncentrerer signalet ved at subtrahere dele af lydens overtonemønster. Og hovedsageligt temporale modulationseffekter som rumklang, delay, chorus, flanger, phaser, feedback og sustain mangfoldiggør på forskellig måde materialet ved at repetere det i forskudte tidslige afstande omkring det oprindelige signal. 
Hjarvard, Stig. En verden af medier: medialiseringen af politik, sprog, religion og leg. Frederiksberg: Samfundslitteratur, 2008.

Hjortkjær, Jens. Den musikalske masse. Specialeafhandling, Institut for Kunst- og Kulturvidenskab, Københavns Universitet, 2007.

Katz, Mark. Capturing Sound. Berkeley and Los Angeles, CA: University of California Press, 2004. Kealy, Edward R. "From Craft to Art: The Case of Sound Mixers and Popular Music". On Record: Rock, Pop, and the Written Word. Red. Simon Frith \& Andrew Goodwin. London: Routledge, I99o. I72-I84.

Milner, Greg. Perfecting Sound Forever. New York: Faber \& Faber, 2009.

Moorefield, Virgil. The Producer as composer. Cambridge, Mass.: MIT Press, 2005.

Russ, Martin. Sound Synthesis and Sampling. 2. udg. Burlington, MA: Focal Press, 2004.

Schaeffer, Pierre. Traité des objets musicaux. Paris: Seuil, I966.

Tamm, Eric. Brian Eno: His Music and the Vertical Color of Sound, New York: Da Capo Press, I995.

Thebérge, Paul. Any Sound You Can Imagine: Making Music/Consuming Technology. Middletown, CT:

Wesleyan University Press, 1997.

Williams, Richard. Phil Spector - Out Of His Head. London: Omnibus Press, 2003.

Zak, Albin. The Poetics of Rock: Cutting Tracks, Making Records. Berkeley and Los Angeles, CA: University of California Press, 200I. 
ANMELDELSER 